\title{
Correction to: Evolution of a Novel Robotic Training Curriculum in a Complex General Surgical Oncology Fellowship
}

L. Mark Knab, MD ${ }^{1}$, Mazen S. Zenati, MD, MPH, PhD ${ }^{1}$, Anton Khodakov, BS ${ }^{1}$, Maryjoe Rice, BS ${ }^{1}$, Amr Al-abbas, MD $^{1}$, David L. Bartlett, MD ${ }^{1}$, Amer H. Zureikat, MD ${ }^{1}$, Herbert J. Zeh, MD ${ }^{2}$, and Melissa E. Hogg, MD, MS ${ }^{1}$

${ }^{1}$ Division of Surgical Oncology, University of Pittsburgh Medical Center, Pittsburgh, PA; ${ }^{2}$ Department of Surgery, University of Texas Southwestern, Dallas, TX

\section{CORRECTION TO: ANN SURG ONCOL (2018) 25:3445-3452}

\section{HTTPS://DOI.ORG/10.1245/S10434-018-6686-0}

In the XML of the original article, L. Mark Knab's first name was tagged incorrectly.

The original article can be found online at https://doi.org/10.1245/ s10434-018-6686-0.

(C) Society of Surgical Oncology 2018

Published Online: 12 December 2018

M. E. Hogg, MD, MS

e-mail: hoggme@upmc.edu 